\title{
Structures and Properties of Self - crosslinking Silicone Resin
}

\author{
Yong-xin Zhao, and Ying-qiang Zhang* \\ Shanghai Institute of Technology, School of Materials Science and Engineering, Shanghai, 201418
}

\begin{abstract}
Highly transparent silicone resin with self-crosslinking structure was prepared using phenyltrimethoxysilane, diphenyldimethoxysilane, 1,3,5,7-cyclotetra(methyl siloxane) and bisvinyltetramethyldisiloxane as main raw materials. The structure of silicone resin was determined by Fourier Transform Infrared Spectroscopy (FT-IR). The light transmittance was measured by UV-Vis spectroscopy. Thermogravimetric analysis (TGA) was used to study the thermal decomposition process. The microstructure of cured self-crosslinking silicone resin is more uniform, resulting in better light transmittance up to $100 \%$ in the range of $400 \mathrm{~nm} \sim 800 \mathrm{~nm}$. The cured has relatively good heat resistance, the initial thermal decomposition temperature of the cured could be up to $315.8{ }^{\circ} \mathrm{C}$. SEM observations show that the self-crosslinking silicone has a uniform, textured structure, higher transparency compared with the existing condensation silicone material, and can be used as advanced architectural translucent materials and optics packaging materials.
\end{abstract}

\section{Introduction}

Silicone resin has the advantages of high light transmittance, high refractive index, high thermal stability, high yellowing resistance, low temperature resistance, etc. It is currently the most widely used optical packaging material, which is widely used in the field of construction sealing, the packaging of solar energy, high power LEDs and optical devices ${ }^{[1-3]}$. In recent years, with the rapid development of high-rise buildings, and research of connecting materials and new construction seals shows active, there are new and higher requirements for the light transmittance and heat resistance of packaging materials. The research in this field of technology is very promising ${ }^{[4]}$.

At present, double-packed condensation silicones sealing materials, such as dow corning's GP300, GP800, 1-2577 and shin-etsu's KE445 and KR251, and other double-packed addition types used in the construction lighting industry. However, there are some problems in double-package silicone adhesives: Mixed unevenness is almost present in all types of two-component silicone adhesives. For instance, when the refractive index difference between vinyl phenyl silicone resin and crosslinking agent is large, the difference in the molecular structure between the two is large, so the compatibility becomes worse. When the two are mixed and cured, it is difficult to achieve uniform microscopic mixing and full curing, resulting in a decrease in the light transmission performance of the sealant. So it is difficult to meet the development needs of high-end light transmissive materials. In order to overcome the above problems, the author has recently tried a preparation technique of a self-crosslinking silicone resin (which integrates $\mathrm{Si}-\mathrm{H}$ bonds and Si-vinyl groups into one molecular structure through chemical synthesis), That is, through the redesign and integration of the curing groups in the molecular structures of methylphenyl vinyl silicone resins and methylphenyl hydrogen-containing silicone oils, a highly light-transmitting encapsulating material is prepared by utilizing the chemical structural compatibility ${ }^{[5-6]}$. This technology adjusts the amount and proportion of monomers, selects the appropriate feeding sequence and feeding method, and controls the appropriate reaction temperature and polymerization time. The prepared packaging adhesive has adjustable viscosity, uniform composition, high light transmittance and heat resistance. It is expected to be used as an encapsulation material for advanced architectural light transmission materials and optical devices. Selfcrosslinking silicone resin was prepared in this paper, and the structures and properties of its cured product were analyzed.

\section{Experimental}

\subsection{Materials}

Phenyltrimethoxysilane, diphenyldimethoxysilane, 1,3,5,7-cyclotetra (methyl siloxane) and bisvinyltetramethyldisiloxane, industrial grade, commercial; toluene, analytical grade, Shanghai Titan Technology Co., Ltd.

\subsection{Preparation and Curing of Self-crosslinking Silicone Resins}

\footnotetext{
*Yingqiang Zhang: sh_yqzhang@sina.com
} 
According to stoichiometry, phenyltrimethoxysilane, diphenyldimethoxysilane, 1,3,5,7-cyclotetra(methyl siloxane) and bisvinyltetramethyldisiloxane, distilled water, toluene and concentrated sulfuric acid were weighed into a $500 \mathrm{ml}$ four-necked flask with a spherical condenser tube. The temperature was raised to $65^{\circ} \mathrm{C}$, stirred at a constant temperature for 3 hours, and then heated to $100^{\circ} \mathrm{C}$. Stirring was continued at a constant temperature for 5 hours. Heating was stopped, and the mixture was poured into a separatory funnel. The lower layer liquid was removed out, then added sodium carbonate solution, and washed to neutral. The lower layer liquid was distilled to obtain the product. The synthesis route is shown in Scheme 1. The curing reaction of the self-crosslinking silicone resin is shown in Scheme 2.

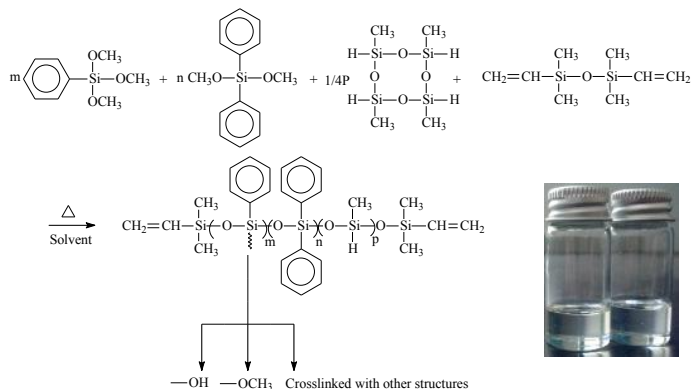

Scheme 1 Synthesis process of self-crosslinking silicone resin

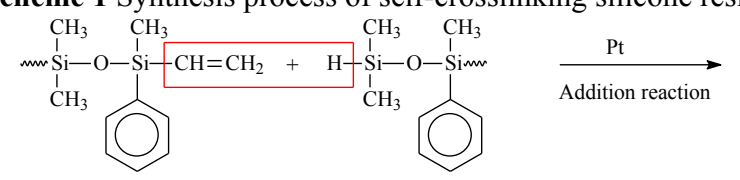

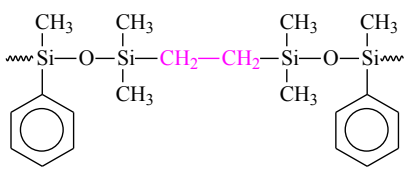

Scheme 2 Curing crosslinking reaction of silicone resin

\subsection{Test equipment and methods}

A self-crosslinking silicone resin was added with a 3\% platinum complexed curing agent and cured at $150^{\circ} \mathrm{C}$ for a certain period of time to prepare a sample with a thickness of $1 \mathrm{~mm}$. The air was used as a reference and UV757CRT UV-visible spectrometer was used for analyzing the transmittance of sample, testing wavelength range was from $200 \mathrm{~nm}$ to $800 \mathrm{~nm}$. The thermal decomposition analysis of the cured product was carried out using a German TG synchronous thermal analyzer. The heating range was from $25^{\circ} \mathrm{C}$ to $300^{\circ} \mathrm{C}$ and the heating rate was $10^{\circ} \mathrm{C} / \mathrm{min}$. The morphology of the material was tested using a Quanta 200 FEG scanning electron microscope (SEM) from FEI, the Netherlands.

\section{Results and discussion}

\subsection{FT-IR analysis}

The FT-IR spectroscopy of self-crosslinking silicone resin of before and after curing is shown in Fig.1.

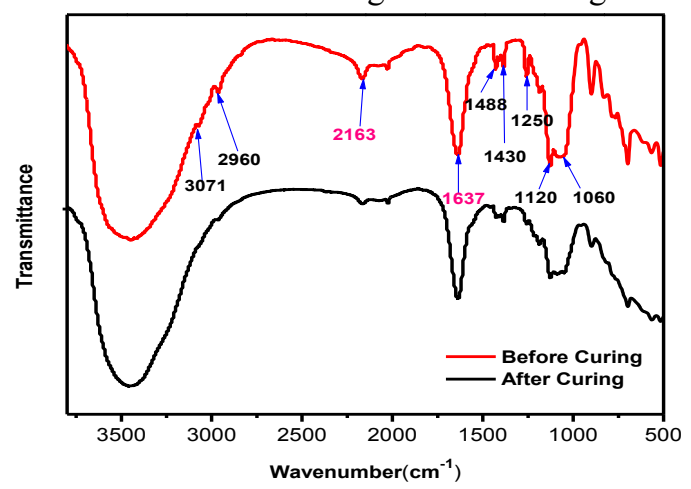

Fig.1 The infrared spectra (FT-IR) were compared with before and after curing

FT-IR $\left(500-4000 \mathrm{~cm}^{-1}, \mathrm{v}\right): 3071 \mathrm{~cm}^{-1}(\mathrm{Ph}-\mathrm{CH} 2=\mathrm{CH}-)$; $2960 \mathrm{~cm}^{-1} \quad(-\mathrm{CH} 3) ; 2163 \mathrm{~cm}^{-1} \quad(-\mathrm{Si}-\mathrm{H}) ; 1637 \mathrm{~cm}^{-1} \quad(-$ $\left.\mathrm{CH}=\mathrm{CH}_{2}\right) ; 1488 \mathrm{~cm}^{-1}(-\mathrm{Ph}) ; 1430 \mathrm{~cm}^{-1}$ and $1120 \mathrm{~cm}^{-1}(-\mathrm{Si}-$ $\mathrm{Ph}) ; 1250 \mathrm{~cm}^{-1}\left(-\mathrm{Si}_{-} \mathrm{CH}_{3}\right) ; 1060 \mathrm{~cm}^{-1}$ (Si-O-Si). The FTIR data indicate the synthetic silicone resin consisting of $-\mathrm{Si}-\mathrm{H},-\mathrm{CH}=\mathrm{CH}_{2},-\mathrm{Si}-\mathrm{Ph}$ and other structures. And the skeleton vibration peak of $\mathrm{Si}-\mathrm{O}-\mathrm{Si}$ is a strong broad peak, indicating that the $\mathrm{Si}-\mathrm{O}-\mathrm{Si}$ structure is a chain which was the structure of the copolymerization formed in the condensation reaction. After curing, the signal for $2163 \mathrm{~cm}^{-1} \quad(-\mathrm{Si}-\mathrm{H})$ and $1637 \mathrm{~cm}^{-1} \quad\left(-\mathrm{CH}=\mathrm{CH}_{2}\right)$ got weakened, which indicated that hydrosilylation addition reaction was conducted while curing.

\subsection{Transmittance analysis}

As can be seen from Fig. 2, the light transmittance of the product is almost $100 \%$ in the range of $400 \mathrm{~nm}$ to 800 $\mathrm{nm}$. There are two main reasons for the higher light transmittance of the self-crosslinking silicone resin. First, in order to increase the light transmission properties of the cured product, the density of crosslink bonds is appropriately reduced in the design of its molecular structure. The molecular structure of the resin contains both vinyl groups, $\mathrm{Si}-\mathrm{H}$ bonds, which do not require the addition of a cross-linking agent when it is cured. Under the action of the catalyst, the vinyl and $\mathrm{Si}-\mathrm{H}$ bonds of its own molecular structure mutually reacts with each other. An addition reaction can occur, that is, without involving a conventional two-pack silicone resin mixing process, the curing structure of the silicone resin becomes relatively simple, so that the cured product achieves the uniformity of the microstructure.

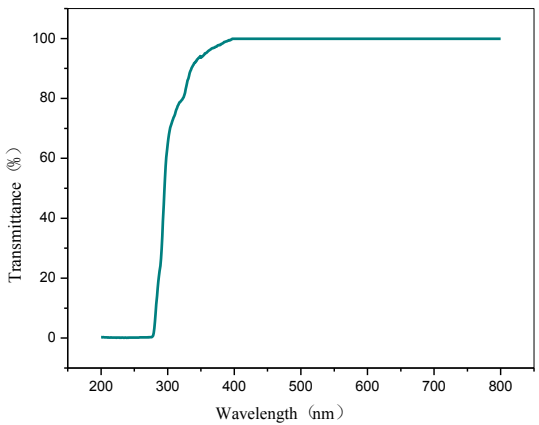

Fig.2 Transmittance curves of sample 


\subsection{TG-DTG analysis}

From Fig. 3, it can be seen that the cure reaction of selfcrosslinking silicone resin is relatively complete, and its relatively perfect cross-linking structure of the cured product makes it have a higher thermal decomposition temperature. From Fig. 3, it can be seen that the cured product has a high initial thermal decomposition temperature of $315.8^{\circ} \mathrm{C}$. The thermal decomposition process is a one-stage reaction. During the thermal decomposition process, when the temperature rises as high as $500^{\circ} \mathrm{C}$, the silicon resin backbone-Si-O-Si- is largely degraded by the ring, and the bonds break into rings of various sizes, and the weight loss rapidly increases. After that, the system reaches the maximum degradation rate.

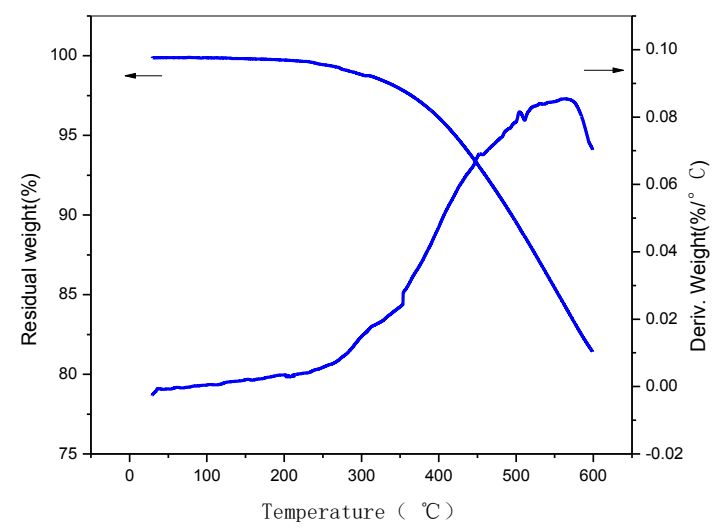

Fig. 3 TG-DTG curves of different samples

\subsection{SEM analysis}

SEM image of the cured product surface with different cure times were shown in Fig. 4. Comparing Fig. 4 (a), (b), (c) and (d), it can be seen that the four products have similar cured structures and all exhibit a uniform and textured structure. With the prolongation of the curing time, the texture structure appears more, which indicates that the heat resistance is getting better and the light transmission is slightly reduced.

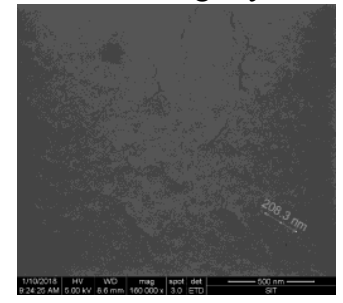

(a)

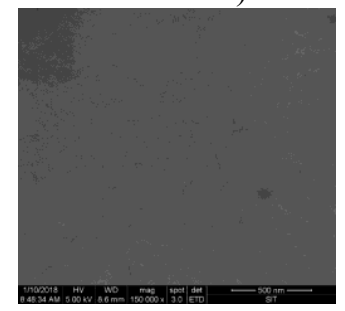

(c)

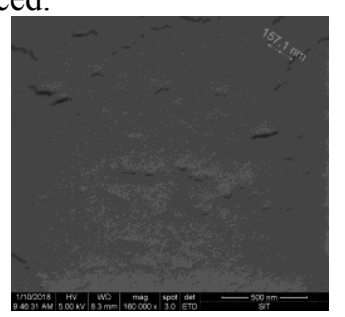

(b)

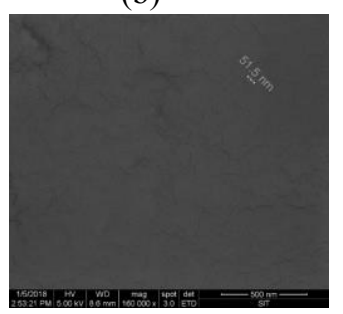

(d)
Fig. 4 SEM picture s of samples with different cure times (a) $10 \mathrm{~min}$; (b) $20 \mathrm{~min}$; (c) $30 \mathrm{~min}$; (d) $60 \mathrm{~min}$

\section{Conclusion}

Different proportions of self-crosslinking silicone resins were prepared and their light transmission and thermal properties were investigated. The conclusions are as follows: The structure of silicone resin was determined by Fourier Transform Infrared Spectroscopy (FT-IR). Self-crosslinking silicone resins have a uniform microstructure with good light transmission. Transmittance in the range of $400 \sim 800 \mathrm{~nm}$ can reach $100 \%$. The cured product of the self-crosslinking silicone resin has a relatively good heat resistance, and the cured product has a high initial thermal decomposition temperature of $315.8^{\circ} \mathrm{C}$. SEM observations show that the self-crosslinking silicone has a uniform, textured structure

\section{References}

1. JANG S J, YUN H D, LEE M S. Effects of stiffening sealant thickness on the structural performance of structural silicone glazing (SSG) sealantconnections in curtain wall systems[J]. Archives of Civil and Mechanical Engineering, 2017, 17(1): 65-74.

2. BUYL F D. Silicone sealants and structural adhesives. International Journal of Adhesion and Adhesives, 21 (5) (2001), pp. 411-422.

3. PANTALEO A, ROMA D, PELLERANO A. Influence of wood substrate on bonding joint with structural silicone sealants for wood frames applications $[\mathrm{J}]$. International Journal of Adhesion and Adhesives, 2012,37:121-128.

4. PEREZ G G, BURILLO G. Modification of silicone sealant to improve gamma radiation resistance, by addition of protective agents[J]. Radiation Physics and Chemistry, 2013, 90(9): 98103.

5. KIM D S, PARK Y S. 10、Zhang Yingqiang, Zhao Yongxin, Li Ye. Single-package silicone rubber encapsulant for high-power white light LED and preparation method thereof[P]. ZL2014104712166, 2016.08.24.

6. Zhang Yingqiang, Zhang Linlin, Wu Zhen. Highviscosity self-crosslinking LED encapsulant resin and its preparation method[P]. ZL2014104712753, 2017.06.23. 